\title{
248 A STUDY OF RISK ASSESSMENT INDEX TO PREDICT CARDIOVASCULAR DISEASES AMONG YOUNG ADULTS (AGED 20-40 YEARS)
}

Pratibha Singh,' Mani Paliwal' ${ }^{1}$ Manav Rachna International University, Faridabad, Harayana, India; ${ }^{2}$ Dr BR Ambedkar University, Agra, Uttar Pradesh, India

10.1136/bjsm.2010.078725.248

Every year cardiovascular diseases (CVDs) claim 5-6 million lives which account for $64 \%$ of all deaths reported in India. About one-fourth of these deaths occur in people below the age of 45 years. Therefore, in the present study 100 young adults was undertaken to predict the CVDs among young adults (aged 20-40 years) in the urban area of Mainpuri city, UP, with the main objectives to calculate and compare the risk assessment index among various groups of study and to correlate the risk assessment index with various socio-economic and demographic variables among the study population. These 100 cases were selected through multistage sampling technique and following findings were observed: (1) the high mean risk assessment score was found to be only in $8.0 \%$ of the total study subject. Mean risk assessment score was found to be high in males, aged 30-40 years, smokers, coffee/tea and alcohol users. (2) Higher risk was also observed among the respondents having family history of CVD with stressful life and did not perform any exercise. According to food pattern the mean risk assessment was found high among the respondents, who end feasts with ice-cream, sweets, take cakes and pastry in between meals, using saturated fat in the diet. (3) The mean intake of calories, protein, vitamin $A$, vitamin $B_{1}$, riboflavin, vitamin $C$, iron, fat were found to be higher among high risk group and positively correlated with risk assessment scores among the study population. (4) Risk assessment score was also found to be positively correlated with age, family type, monthly income, body mass index and waist to hip ratio of the respondents. 